\title{
Efectos de la interferencia lingüistica en la adquisición y transferencia de discriminaciones condicionales con tareas de igualación de la muestra de primer y segundo orden
}

\author{
Alejandro León ${ }^{* 1}$, Carlos Zenteno², Isiris Guzmán² e Iván Felipe Medina-Arboleda ${ }^{3}$ \\ ${ }^{1}$ Universidad Veracruzana, CEICAH, México, ${ }^{2}$ Universidad Nacional Autónoma de México, México, \\ ${ }^{3}$ Universidad Católica de Colombia, Colombia
}

Recibido, julio 15/2016

Concepto de evaluación, agosto 26/2016

Aceptado, diciembre 5/2016
Referencia: León, A., Zenteno, C., Guzmán, I. \& MedinaArboleda, I.F. (2017). Efectos de la interferencia lingüística en la adquisición y transferencia de discriminaciones condicionales con tareas de igualación de la muestra de primer y segundo orden. Acta Colombiana de Psicología. 20(2), 53-68. doi: http://www.dx.doi.org/10.14718/ ACP.2017.20.2.4

Resumen

En el estudio de la discriminación condicional (DC) en humanos se ha descrito que el contacto lingüístico con las propiedades y criterios de la tarea tiene una gran importancia para la adquisición y la transferencia de la misma, especialmente para las pruebas de tipo extrarrelacional y extradimensional. Sin embargo, estudios empíricos y conceptuales recientes cuestionan dicho supuesto. En estudios previos se han agregado componentes lingüísticos, pero no se ha explorado sistemáticamente el efecto de su restricción a través de tareas que compitan con la actividad verbal con respecto a tareas, como la interferencia lingüística. En el presente estudio se realizaron dos experimentos — uno con tareas de igualación de primer orden (TIMPO) y otro con tareas de segundo orden (TIMSO) - con el objetivo de evaluar el efecto de la interferencia lingüística sobre la adquisición de una DC y en el ajuste funcional en pruebas de transferencia (extrainstancia, extramodal, extrarrelacional y extradimensional). En los dos experimentos se utilizó un diseño $\mathrm{N}=1$, en el que participaron 24 estudiantes universitarios en total — doce en cada estudio-, y se contrastaron los efectos de dos condiciones experimentales: una con con interferencia y otra sin interferencia - con seis participantes para cada condición - . Los hallazgos sugieren que la interferencia en el contacto lingüístico no afecta la adquisición de la DC ni en TIMPO ni en TIMSO, pero sí afecta el ajuste en pruebas de transferencia, pues en estas se observaron efectos diferenciales por tipo, tanto en TIMPO como en TIMSO.

Palabras clave: Discriminación condicional, transferencia, desligamiento funcional, igualación de la muestra, tarea de interferencia lingüística.

\section{Effects of linguistic interference on the acquisition and transfer of conditional discriminations with first-and second-order matching-to-sample tasks}

\begin{abstract}
Studies on conditional discrimination (CD) in humans have pointed out that linguistic contact with the properties and criteria of the task is critical both for acquisition and transfer, especially in extra-relational and extra-dimensional tests. Recent empirical and conceptual analyses have challenged this assumption. Studies in the field have generally included linguistic components, but the effect of linguistic restriction through tasks that compete with verbal activity regarding tasks, such as linguistic interference, has not yet been systematically explored. Two experiments were conducted: the first one used firstorder matching-to-sample tasks (FOMST) and the second used second-order matching-to-sample tasks (SOMST), aiming to evaluate the effect of a linguistic interference task on the acquisition of conditional discrimination and functional adjustment in transfer tests (extra-instance, extra-modal, extra-relational, and extra-dimensional). Both experiments used an $\mathrm{n}=1$ design. A total of 24 college students participated, 12 in each study, and the effects of two experimental conditions were tested (Interference and No Interference, with six participants in each condition per study). The findings suggest that interference in linguistic contact does not affect the acquisition of CD in FOMST or in SOMST, but it does affect the adjustment in transfer tests. In these, differential effects, by type, were observed in FOMST and SOMST.

Key words: Conditional discrimination, transfer, functional detachment, matching to sample, linguistic interference task.
\end{abstract}

\footnotetext{
* Investigador Titular, Centro de Estudios e Investigaciones en Conocimiento y Aprendizaje Humano, Universidad Veracruzana. Av. Orizaba 203 (Frac. Veracruz), 91020 Xalapa, Ver. (México), aleleon@uv.mx
} 


\title{
Efeitos da interferência linguística na aquisiçâo e na transferência de discriminaçôes condicionais com tarefas de igualação da amostra de primeira e segunda ordem
}

\begin{abstract}
Resumo
No estudo da discriminação condicional (DC) em humanos, tem-se descrito que o contato linguístico com as propriedades e os critérios da tarefa tem uma grande importância para a aquisição e a transferência dela, especialmente para os testes de tipo extrarrelacional e extradimensional. Contudo, estudos empíricos e conceituais recentes questionam essa suposição. Em estudos prévios, têm se acrescido componentes linguísticos, mas não se tem explorado sistematicamente o efeito de sua restrição por meio de tarefas que compitam com a atividade verbal a respeito de tarefas como a interferência linguística. Neste estudo, realizaram-se duas experiências —uma com tarefas de igualação de primeira ordem (Timpo) e outra com tarefas de segunda ordem (Timso) — com o objetivo de avaliar o efeito da interferência linguística sobre a aquisição de uma DC e sobre o ajuste funcional em testes de transferência (extrainstância, extramodal, extrarrelacional e extradimensional). Nas duas experiências, utilizou-se um desenho $\mathrm{N}=1$, do qual participaram 24 estudantes universitários no total — 12 em cada estudoe contrastaram-se os efeitos de duas condições experimentais: uma com interferência e outra sem interferência —com seis participantes para cada condição-. Os achados sugerem que a interferência no contato linguístico não afeta a aquisição da DC nem em Timpo nem em Timso, mas sim afeta o ajuste em testes de transferência, pois nestes se observam efeitos diferenciais por tipo tanto em Timpo quanto em Timso.

Palavras-chave: discriminação condicional, transferência, desligamento funcional, igualação da amostra, tarefa de interferência linguística.
\end{abstract}

\section{INTRODUCCIÓN}

En el marco de la propuesta de Ribes y López (1985), los trabajos fundacionales del programa de investigación en comportamiento humano se han dirigido a indagar sobre las condiciones en las que emerge el comportamiento complejo; entendido como aquel que, vía la mediación lingüística, se desliga o se vuelve autónomo de las propiedades físicoquímicas de los objetos y de la situacionalidad episódica de la interacción. Por ejemplo, la tarea de igualación de la muestra, empleada en el estudio de la discriminación condicional, resultó útil como ejemplar metodológico base para el estudio del comportamiento humano en virtud de que en esta la función vigente de un estímulo no se configura por sus propiedades físicas absolutas, sino por sus relaciones vigentes con otros estímulos ensayo a ensayo (Pérez-Fernández, 2015).

En ese programa de investigación, el desligamiento funcional se predica respecto de las situaciones particulares de entrenamiento con base en la ejecución del participante en situaciones de prueba denominadas pruebas de transferencia. En estas, el supuesto es que en tanto hay variaciones del entrenamiento, las pruebas permiten identificar qué tan ligado quedó la forma de responder del individuo a las cualidades particulares del entrenamiento (León, 2015), entre las que se encuentran las instancias, modalidades, relaciones y dimensiones. Estas pruebas de transferencia son cuatro:
Prueba extrainstancia: también denominada prueba intramodal, en la que se emplean instancias diferentes a las del entrenamiento y se mantienen constantes las modalidades, relaciones y dimensiones.

Prueba extramodal: en la que se varían las modalidades relevantes para la igualación y se mantienen constantes las relaciones y dimensiones.

Prueba extrarrelacional: donde se varían las relaciones pertinentes y se mantienen constantes las dimensiones.

Prueba extradimensional: donde se cambia la dimensión o dominio a la pertenecen los estímulos.

Se supone que altos porcentajes de respuestas correctas únicamente en las pruebas extrainstancia y extramodal indican un contacto funcional estrictamente perceptual con la tarea y, por tanto, un comportamiento situacional que se desliga de las instancias y modalidades, pero que está ligado a los criterios de relación y al dominio del entrenamiento (Ribes et al., 2005; Ribes \& Serrano, 2006). Por otra parte, altos porcentajes de respuestas correctas en las pruebas extrarrelacionales son evidencia de un comportamiento regulado lingüísticamente; esto bajo el supuesto de que responder efectivamente ante las variaciones en el criterio de relación - desligándose del criterio específico entrenado - solo puede tener lugar cuando el comportamiento del individuo es mediado lingüísticamente (Ribes, 1990; Ribes \& Serrano, 2006). Y, finalmente, altos porcentajes de respuestas correctas en pruebas extradimensionales también se considera como evidencia de comportamiento regulado lingüísticamente, ya que para lograrlo se debería abstraer 
y formular lingüísticamente la relación de contingencias que estructura la interacción; independientemente de las instancias, modalidades, criterios de relación y dominios específicos. En este contexto, la interacción se desliga de todo episodio particular o situacional y se actualiza ante instancias, modalidades, relaciones y dominios novedosos, por lo que se muestra un comportamiento transituacional.

De manera complementaria al desempeño en pruebas de transferencia extrarrelacional y extradimensional, la elaboración de segmentos lingüísticos tipo regla ha sido considerado como evidencia de mediación lingüística de las interacciones, (Ribes, Domínguez, Tena \& Martínez, 1992; Ribes \& Martínez, 1990; Ribes, Moreno \& Martínez, 1995a). Dichas reglas son conceptuadas como segmentos lingüísticos que cumplen con las siguientes características: a) son descripciones generales de las relaciones de contingencia que estructuran las interacciones - al margen de cualquier episodio específico-; b) se generan a partir de la ejecución instrumental variada y efectiva; y c) el comportamiento del individuo se ajusta a las relaciones de contingencia descritas por el segmento lingüístico (Ribes, 2000).

Si bien inicialmente se supuso que la ejecución instrumental, variada y efectiva era prerrequisito para la emergencia de segmentos tipo regla, en otros estudios se observó que no era suficiente para la generación de tales segmentos (Trigo, Martínez \& Moreno, 1995). En este contexto, para identificar las condiciones involucradas en la generación de descripciones tipo regla, adicionales al comportamiento instrumental efectivo, se exploró el efecto de diferentes factores, que pueden agruparse de acuerdo al modo de contacto implicado, o promovido, en la tarea: a) contactos observacionales (Moreno, Ribes \& Martínez, 1994; Ribes, Barrera \& Cabrera, 1998; Ribes \& Castillo, 1998; Ribes, Moreno \& Martínez, 1995b; Ribes, Torres \& Barrera, 1995); y b) contactos con morfología lingüística explícita (Cepeda, Hickman, Moreno \& Ribes, 1991; Ribes et al., 1992; Ribes, et al., 1995a; Ribes \& Serrano, 2006).

Con respecto a estos últimos factores se encontró que el contacto lingüístico con las propiedades y criterios de la tarea era crítico en la adquisición de la discriminación condicional en entrenamiento y en su transferencia, especialmente en aquella de tipo extrarrelacional y extradimensional. Sin embargo, trabajos recientes de revisión conceptual y de carácter empírico concluyen, en sentido opuesto, que no hay una relación positiva entre la práctica efectiva en situaciones de prueba y el comportamiento lingüísticamente regulado; y que la generación de descripciones tipo regla no está asociada necesariamente con desempeños altos en las pruebas, incluidas las de tipo extrarrelacional (León, 2015; Peña, Ordóñez, Fonseca \& Fonseca, 2012).
Ahora bien, la mayoría de los estudios dirigidos a identificar el papel funcional de interactuar lingüísticamente con la tarea - a lo que de ahora en adelante se denominará contacto lingüistico - se limitaron a evaluar el efecto de agregar componentes lingüísticos (Cepeda et al, 1991; Ribes et al., 1992; Ribes et al., 1995a; Ribes \& Serrano, 2006). Un hallazgo consistente de dichos estudios es que tanto la adquisición como la transferencia de una discriminación condicional se ven usualmente favorecidas cuando se agregan componentes descriptores del propio desempeño en el entrenamiento. Sin embargo, no se ha explorado sistemáticamente el efecto de interferir el contacto lingüístico; $\mathrm{y}$, de hecho, se supone, que este tiene lugar fundamentalmente cuando se solicitan explícitamente respuestas convencionales a los participantes (Cepeda et al., 1991; Ribes et al., 1992; Ribes et al., 1995a; Ribes \& Serrano, 2006), o cuando las relaciones de igualación se basan en las propiedades convencionales de los eventos; esto asumiendo que cuando no es el caso, el contacto es estrictamente perceptual, es decir, fisico-químico o no lingüístico (Guzmán-Díaz \& Serrano, 2013).

Un ejemplo de lo anterior lo presentan en Guzmán-Díaz y Serrano (2013), quienes emplearon una tarea de igualación de la muestra de segundo orden donde utilizaron números como estímulos. Dicho estudio tuvo tres condiciones: una lingüística, una fisicoquímica, y una redundante. En la primera, las relaciones de igualación se basaron en operaciones aritméticas (igualdad, suma y resta); en la segunda, las relaciones se basaron en la tipografía y en el color de los estímulos (identidad, semejanza en color y diferencia); y en la tercera, las relaciones de igualación se basaron redundantemente en operaciones aritméticas, tipografía y el color de los números. Todos los participantes fueron expuestos a ensayos de prueba - similares a los implementados en el entrenamiento para cada grupo- $-\mathrm{y}$ a ensayos utilizando figuras geométricas y relaciones de igualación por identidad, semejanza en color y semejanza en forma. La adquisición de la $\mathrm{DC}$ fue ligeramente más rápida para la primera condición, sin embargo, en algunas pruebas no hubo diferencias robustas entre la primera y la segunda condición. Para finalizar, los autores reconocen que lo encontrado no concuerda con el planteamiento inicial del experimento acerca del carácter lingüístico o fisicoquímico de cada uno de los arreglos; sin embargo, lo cierto es que con los arreglos metodológicos típicamente empleados es difícil identificar la cualidad del ajuste como función de la presencia o ausencia del contacto lingüístico, pues este generalmente no se limita. En consecuencia, es difícil sostener si se tiene un contacto estrictamente perceptual o uno lingüístico con la tarea. 
Lo anterior es relevante porque en la literatura se han señalado tres posibles tipos de contacto funcional con la tarea de igualación de la muestra (Ribes, 1990; Ribes et al., 2005): el perceptual/situacional, el verbal-modal/extrasituacional, y el verbal-criterio/transituacional. Cada uno de los cuales es identificable a partir de los tipos de pruebas de transferencia, y cuyo requerimiento conductual para su solución es de complejidad diferencial y creciente. Bajo este supuesto, el ajuste funcional verbal-modal, que implica un desligamiento extrasituacional y que es identificable en pruebas extrarrelacionales, debería verse afectado negativamente si se interfiriera el contacto lingüístico. Lo mismo que el ajuste funcional verbal-criterio, que implica un desligamiento transituacional, identificable en pruebas extradimensionales.

Sin embargo, como se señaló previamente, hay evidencia empírica que sugiere que el ajuste exitoso en las pruebas extrarrelacionales no está asociado con descripciones pertinentes del desempeño, lo que hace admisible cuestionar si, en efecto, para desempeñarse efectivamente en este tipo de pruebas se requiere de un contacto verbal-modal con desligamiento extrasituacional, o si es suficiente con un contacto perceptual con desligamiento situacional. Por extensión, es razonable cuestionar lo mismo para las pruebas extradimensionales. De este modo, una forma de contribuir a elucidar la controversia es identificar la cualidad del ajuste afectado en las pruebas por la interferencia del contacto lingüístico durante el entrenamiento.

En un estudio realizado por Delgado, Medina y Soto (2011), utilizando la tarea de igualación de la muestra de primer orden, se variaron sistemáticamente las condiciones de presentación de tareas interferentes de carácter lingüístico con el fin de limitar la producción verbal de los participantes respecto a la tarea. Así, la exposición a las condiciones de interferencia tuvo lugar durante la fase de entrenamiento, siendo las estrategias repetir en "voz alta" un listado de palabras durante la fase de entrenamiento; contar hacia atrás y en cantidades restadas de tres progresivamente números de 1000 a 0 ; y seguir en voz alta la narración del audiolibro "El Principito".

Los resultados de este estudio muestran que los diferentes tipos de exposición a tareas que limitan la producción de segmentos lingüísticos no impidieron la adquisición de la discriminación condicional ni la formación de relaciones de equivalencia. Estos hallazgos sugieren que incluso en situaciones que interfieren en el contacto lingüístico se presenta la adquisición y transferencia de una discriminación condicional en tareas de igualación de la muestra de primer orden (Delgado et al., 2011).

De lo anterior, puede decirse que en la igualación de primer orden la única manera en que el participante puede identificar el criterio de igualación es a través de la retroalimentación, la cual tiene una función discriminativa fundamental. En contraste, en la igualación de la muestra de segundo orden, los estímulos de segundo orden ejemplifican el criterio de igualación. Por ejemplo, Ribes y Torres (2001) señalan que para que esto ocurra, el participante debe reconocer verbalmente dicho criterio aunque el reconocimiento no sea explícito, lo que supondría una diferencia cualitativa entre las interacciones en tareas de primer y segundo orden, siendo en estas últimas más relevante el contacto lingüístico con la tarea. Así, si es el caso, la interferencia con el contacto lingüístico tendría un efecto diferencial en tareas de igualación de primer y segundo orden.

Con base en lo anterior, en el presente estudio, con el objetivo de evaluar el efecto de una tarea de interferencia lingüística sobre la adquisición de una discriminación condicional y el ajuste en pruebas de transferencia en tareas de igualación de primer y segundo orden, se planearon dos experimentos: uno con tareas de primer orden (Experimento I) y otro con tareas de segundo orden (Experimento II). Con estos, se buscó dar respuesta a los interrogantes: ¿la interferencia del contacto lingüístico afecta la adquisición $\mathrm{y}$ transferencia de una discriminación condicional?, ¿la interferencia del contacto lingüístico afecta diferencialmente el tipo de ajuste del individuo en pruebas de transferencia?, ¿las pruebas de transferencia que típicamente se han considerado como evidencia del comportamiento mediado lingüísticamente - extrarrelacional y extradimensional-, en efecto, requieren críticamente de dicha mediación?, y, por último, ¿la interferencia del contacto lingüístico afecta diferencialmente el ajuste conductual en tareas de igualación a la muestra de primer y segundo orden?

\section{EXPERIMENTO I}

\section{MÉTODO}

\section{Participantes}

Participaron voluntariamente doce estudiantes universitarios de la Universidad Nacional Autónoma de México (México) de entre 18 y 23 años de edad sin experiencia en tareas de igualación de la muestra.

\section{Aparatos y situación experimental}

El experimento se llevó a cabo en un laboratorio de cómputo para la condición sin tarea de interferencia lingüística (cursor como dispositivo de respuesta), y en un cubículo 
individual para la condición de tarea de interferencia lingüistica. La tarea experimental y el registro se presentaron de forma automática en el programa Superlab 4.0.

\section{Diseño}

En el presente estudio se utilizó un diseño experimental intrasujeto $(\mathrm{n}=1)$. Se utilizó la tarea de igualación de la muestra de primer orden (TIMPO), con dos condiciones: a) con tarea de interferencia lingüística (en adelante, con TIL); y b) sin tarea de interferencia lingüistica (ahora, sin TIL). Los participantes fueron asignados aleatoriamente a las condiciones, y así se conformaron dos grupos de seis participantes. Las condiciones del diseño se presentan en la Tabla 1.

\section{Procedimiento}

Los participantes pasaron por las fases de prueba inicial, primer entrenamiento, primera prueba, segundo entrenamiento, segunda prueba, tercer entrenamiento y tercera prueba (véase Tabla 1). El estudio tuvo lugar en una sola sesión, esto con la finalidad de incrementar la validez interna del estudio y evitar que los participantes se comunicaran entre sí o intercambiaran información que pudiera afectar su desempeño en las tareas.

Se utilizó la TIMPO como tarea base, diferenciándose según la condición con o sin TIL. La TIL consistió en que los participantes atendieran al sonido de un metrónomo mientras, simultáneamente, respondían a la tarea de igualación al decir en voz alta una letra del abecedario en orden ascendente siguiendo cada sonido del metrónomo.

En cada ensayo de la TIMPO se presentó un Estímulo Muestra (EM) en la parte superior central de la pantalla, y cuatro Estímulos Comparativos (EC) en la parte inferior de la pantalla dispuestos de forma horizontal. Todos los estímulos - excepto los de tercera prueba - fueron figuras. Los arreglos se diseñaron de modo que en cada ensayo siempre se presentaban comparativos relacionados con el estímulo muestra de la siguiente manera: uno idéntico, uno semejante en forma, uno semejante en color y uno diferente respecto de la muestra (véase Figura 1).
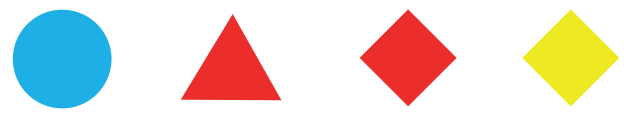

Figura 1. Arreglo estándar de la TIMPO. Fuente: elaboración propia.

\section{Fases del experimento.}

\section{Prueba inicial.}

La prueba inicial consistió en doce ensayos que evaluaban relaciones de identidad, semejanza en color, semejanza en forma y diferencia, que fueron presentados aleatoriamente y sin retroalimentación. El objetivo de esta fase fue identificar la tendencia de los participantes a responder hacia algún criterio de relación. En esta, no se presentó información sobre el desempeño, y las instrucciones que se presentaron para ambos grupos fueron:

En las siguientes pantallas se te presentarán cinco figuras: una en el centro y cuatro en la parte inferior. Elije una de las figuras de abajo que corresponda con la del centro. Para registrar tu respuesta ubica el puntero del "mouse" sobre la figura que escogiste y da clic en el botón izquierdo. Si tienes dudas con las instrucciones del juego pregunta al investigador, si no, da clic en "continuar" para iniciar.

Tabla 1

Condiciones experimentales del Experimento I

\begin{tabular}{|c|c|c|c|c|c|c|c|c|}
\hline Condición & $\begin{array}{c}\text { Prueba } \\
\text { inicial } \\
\text { (12) }\end{array}$ & \multicolumn{2}{|c|}{$\begin{array}{c}1^{\circ} \text { Entrenamiento } \\
\text { (12) }\end{array}$} & $\begin{array}{c}1^{\circ} \text { Prueba } \\
\text { (24) }\end{array}$ & $\begin{array}{c}2^{\circ} \text { Entrenamiento } \\
\text { (12) }\end{array}$ & $\begin{array}{c}2^{\circ} \text { Prueba } \\
\text { (24) }\end{array}$ & $\begin{array}{c}3^{\circ} \text { Entrenamiento } \\
\text { (12) }\end{array}$ & $\begin{array}{l}3^{\circ} \text { Prueba } \\
\text { (12) }\end{array}$ \\
\hline $\begin{array}{l}\text { Con TIL } \\
(n=6)\end{array}$ & $\begin{array}{l}\text { Relaciones } \\
\text { posibles: } \\
\text { identidad, } \\
\text { color, forma } \\
\text { y diferencia. }\end{array}$ & $\begin{array}{l}\text { Entrenamiento } \\
\text { metrónomo. }\end{array}$ & $\begin{array}{l}\text { Similitud } \\
\text { forma. }\end{array}$ & $\begin{array}{l}\text { Intramo- } \\
\text { dal: color y } \\
\text { forma. } \\
\text { Extramo- } \\
\text { dal: forma y } \\
\text { tamaño. }\end{array}$ & $\begin{array}{l}\text { Similitud por } \\
\text { color. }\end{array}$ & $\begin{array}{l}\text { Intramo- } \\
\text { dal: color } \\
\text { y forma. } \\
\text { Extramo- } \\
\text { dal: color } \\
\text { y tamaño. }\end{array}$ & Diferencia. & $\begin{array}{c}\text { Extradimen- } \\
\text { sional: } \\
\text { letras } \\
\text { (vocales) y } \\
\text { tipografía. }\end{array}$ \\
\hline
\end{tabular}




\section{Primer entrenamiento.}

Este consistió en doce ensayos de similitud por forma. Para el caso del grupo TIMPO con TIL, además de resolver la tarea de igualación, los participantes debían atender a la tarea de interferencia lingüistica. Previo a la tarea de igualación, para que se familiarizaran con la TIL, los participantes pasaron por un entrenamiento al metrónomo, en el que decían el abecedario en cada "bip" del metrónomo, sin estar expuestos a la tarea de igualación. Los arreglos de estímulo fueron los mismos para los grupos y se presentaron aleatoriamente. En esta fase se les notificó inmediatamente a los participantes si su respuesta era correcta o incorrecta en una diapositiva posterior con una duración de un segundo. La palabra "correcto" era presentada al centro de la pantalla en letras color verde sobre fondo blanco; mientras que la palabra "incorrecto" era presentada al centro, en letras color rojo sobre fondo blanco. Inmediatamente después de la retroalimentación se le daba inicio al siguiente ensayo. Las instrucciones que se presentaron en todos los entrenamientos para el grupo TIMPO sin TIL fueron:

En las siguientes pantallas se te presentarán cinco figuras: una en el centro y cuatro en la parte inferior. Elije una de las figuras de abajo que corresponda con la del centro. Para registrar tu respuesta ubica el puntero del "mouse" sobre la figura que escogiste y da clic en el botón izquierdo. En esta ocasión se te dirá si tu respuesta fue correcta o incorrecta. Si tienes dudas con las instrucciones del juego pregunta al investigador, si no, da clic en "continuar" para iniciar. Mientras que las instrucciones que se presentaron en todos los entrenamientos para el grupo TIMPO con TIL fueron:

En las siguientes pantallas se te presentarán cinco figuras: una en el centro y cuatro en la parte inferior. Elije una de las figuras de abajo que corresponda con la del centro. Para registrar tu respuesta ubica el puntero del "mouse" sobre la figura que escogiste y da clic en el botón izquierdo. En esta ocasión se te dirá si tu respuesta fue correcta o incorrecta. Además, tendrás que decir una letra del abecedario en orden ascendente, en cada sonido del metrónomo. Si tienes dudas con las instrucciones del juego pregunta al investigador, si no, da clic en "continuar" para iniciar.

\section{Primera prueba.}

La primera prueba estuvo constituida por 24 ensayos de similitud por forma, de los cuales doce correspondían a la prueba intramodal, donde las dimensiones relevantes de los estímulos eran color y forma (véase Figura 2); y los restantes correspondían a la prueba extramodal, donde las dimensiones relevantes eran forma y tamaño (véase Figura 3).
Los arreglos de estímulo utilizados fueron los mismos para ambos grupos y se presentaron aleatoriamente. En este caso no se notificó a los participantes si su respuesta era correcta o incorrecta. Las instrucciones que se presentaron en todas las pruebas fueron:

En las siguientes pantallas se te presentarán cinco figuras: una en el centro y cuatro en la parte inferior. Elije una de las figuras de abajo que corresponda con la del centro. Para registrar tu respuesta ubica el puntero del "mouse" sobre la figura que escogiste y da clic en el botón izquierdo. En esta ocasión no se te informará si tu respuesta es correcta o no. Si tienes dudas con las instrucciones del juego pregunta al investigador, si no, da clic en "continuar" para iniciar.
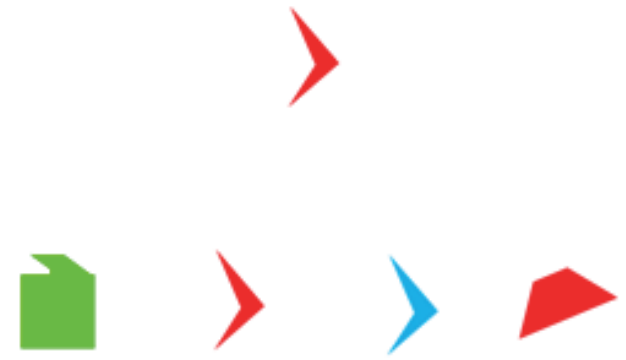

Figura 2. Ejemplo de ensayo de prueba intramodal en la primera prueba. Fuente: elaboración propia.
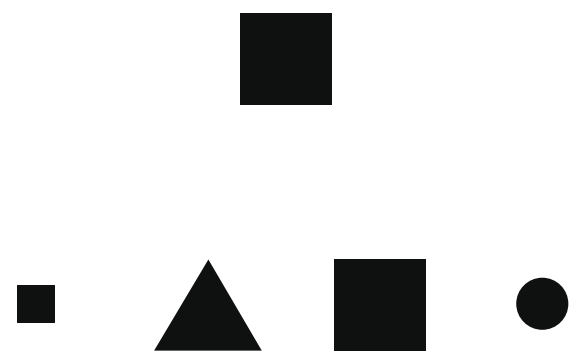

Figura 3. Ejemplo de ensayo de prueba extramodal en la primera prueba. Fuente: elaboración propia.

\section{Segundo entrenamiento.}

Este estuvo conformado por doce ensayos de similitud por color (diferente al primer entrenamiento). Para el caso del grupo TIMPO con TIL, la tarea de igualación se hacía en simultáneo a la TIL. Los arreglos de estímulo utilizados fueron los mismos en los grupos, y se presentaron aleatoriamente. En este caso se notificó si las respuestas eran correctas o incorrectas.

\section{Segunda prueba.}

La segunda prueba estuvo constituida por 24 ensayos, de los cuales doce correspondían a la prueba intramodal, 
donde las dimensiones relevantes de los estímulos eran color y forma (véase Figura 4); y los doce ensayos restantes correspondían a la prueba extramodal, donde las dimensiones relevantes de los estímulos eran color y tamaño (véase Figura 5). Los arreglos de estímulo utilizados fueron los mismos entre grupos, y se presentaron aleatoriamente. Después de responder, no se les dio información sobre el desempeño.
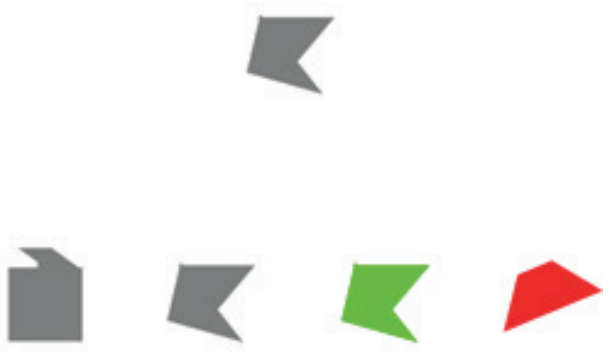

Figura 4. Ejemplo de ensayo de prueba intramodal en la segunda prueba. Fuente: elaboración propia.



Figura 5. Ejemplo de ensayo de prueba extramodal en la segunda prueba. Fuente: elaboración propia.

\section{Tercer entrenamiento.}

Estuvo conformado por doce ensayos de diferencia (diferente al primer y segundo entrenamiento). En el grupo TIMPO con TIL, en simultáneo a la tarea de igualación, los participantes debían atender a la TIL. Los arreglos de estímulo fueron los mismos entre grupos, y se presentaron aleatoriamente. En este caso sí se les informó si su respuesta era correcta o incorrecta.

\section{Tercera prueba.}

La tercera prueba consistió en una prueba extradimensional conformada por doce ensayos de diferencia. En esta fase, los estímulos no eran figuras, sino letras, y la dimensión relevante de los estímulos era la forma y la tipografía (véase Figura 6). Los arreglos de estímulo utilizados fueron los mismos para ambos grupos, y se presentaron aleatoriamente. Acá, no se le dio información sobre el desempeño a los participantes.



Figura 6. Ejemplo de ensayo de la tercera prueba. Fuente: elaboración propia.

\section{RESULTADOS}

El resumen de resultados y los datos de los porcentajes de aciertos individuales agrupados de acuerdo a la condición experimental y según las fases del estudio se muestran en la Tabla 2. Específicamente, el análisis se centra en el contraste de los desempeños individuales a lo largo las diferentes fases, el contraste interindividual al interior de cada grupo - tanto longitudinal como transversalmentey en el contraste de los desempeños individuales entre grupos de manera longitudinal y transversal. En este caso, se fijaron dos criterios de contraste para los desempeños individuales: desempeño por encima del $50 \%$ y desempeño superior al $80 \%$ de aciertos.

El análisis de la prueba de tendencia inicial muestra en los participantes de ambas condiciones una tendencia predominante a responder al criterio de identidad, presentando cuatro respuestas diferentes: tres al criterio de forma ( $\mathrm{p} 1 \mathrm{y}$ p10) y una al criterio de color (p12). En el primer entrenamiento no se identificaron diferencias entre condiciones, y hubo un mayor número de participantes con desempeños superiores al $50 \%$ en la condición sin TIL (p2, p3, p5 y p6), aunque en la condición con TIL fue mayor el número de participantes que obtuvieron desempeños superiores al $80 \%$ (p7, p9 y p10).

En la primera prueba (intramodal y extramodal) no se encontró un efecto diferencial de las condiciones experimentales sobre el desempeño. Los resultados entre participantes muestran una consistencia entre las dos pruebas, así los resultados en la prueba intramodal tuvieran como diferencia máxima respecto de la extramodal tres ensayos correctos (p1, p7 y p10). Cabe señalar que la consistencia entre altos desempeños en la fase de entrenamiento y altos desempeños en la fase de prueba fue notoria para la condición con TIL (p7, p9 y p10).

Por otra parte, en el segundo entrenamiento se encontró una disminución en el desempeño de los participantes, en donde solo tres de ellos obtuvo ejecuciones por encima del 
Tabla 2

Resumen de resultados del Experimento I

\begin{tabular}{|c|c|c|c|c|c|c|c|c|c|}
\hline \multirow[t]{2}{*}{ Participante } & \multirow[t]{2}{*}{$\begin{array}{l}\text { Prueba de } \\
\text { tendencia }\end{array}$} & \multirow[t]{2}{*}{$1^{\circ}$ Entrenamiento } & \multicolumn{2}{|c|}{$1^{\circ}$ Prueba } & \multirow[t]{2}{*}{$2^{\circ}$ Entrenamiento } & \multicolumn{2}{|c|}{$2^{\circ}$ Prueba } & \multirow[t]{2}{*}{$3^{\circ}$ Entrenamiento } & \multirow{2}{*}{$\begin{array}{c}3^{\circ} \text { Pueba } \\
\text { ED }\end{array}$} \\
\hline & & & IM & EM & & IM & EM & & \\
\hline \multicolumn{10}{|c|}{ Condición sin TIL } \\
\hline 1 & $10(\mathrm{I}) 2(\mathrm{~F})$ & 25 & $100 * *$ & $92 * *$ & 33 & 17 & 33 & $83 * *$ & $67 *$ \\
\hline 2 & $12(\mathrm{I})$ & $75^{*}$ & 0 & 0 & $67 *$ & 0 & 8.3 & $58^{*}$ & 0 \\
\hline 3 & $12(\mathrm{I})$ & $83 * *$ & $58 *$ & $75^{*}$ & $75^{*}$ & 17 & $83^{* *}$ & $58^{*}$ & 8.3 \\
\hline 4 & $12(\mathrm{I})$ & 50 & 0 & 0 & 25 & 0 & 0 & $58^{*}$ & 0 \\
\hline 5 & $12(\mathrm{I})$ & $83 * *$ & 0 & 0 & 50 & 8.3 & 8.3 & $58 *$ & 0 \\
\hline 6 & $12(\mathrm{I})$ & $67 *$ & $100 * *$ & $100 * *$ & $67^{*}$ & $100 * *$ & $100 * *$ & $92 * *$ & 50 \\
\hline \multicolumn{10}{|c|}{ Condición con TIL } \\
\hline 7 & $12(\mathrm{I})$ & $83 * *$ & $83 * *$ & $58^{*}$ & 33 & 33 & 50 & 33 & 0 \\
\hline 8 & $12(\mathrm{I})$ & 0 & 0 & 0 & 0 & 0 & 0 & 0 & 0 \\
\hline 9 & $12(\mathrm{I})$ & $83 * *$ & $83 * *$ & $83 * *$ & 0 & 0 & 25 & 0 & 0 \\
\hline 10 & $11(\mathrm{I}) 1(\mathrm{~F})$ & $83 * *$ & $67 *$ & $58^{*}$ & 33 & 0 & 8.3 & 8.3 & 8.3 \\
\hline 11 & $12(\mathrm{I})$ & 8.3 & 50 & $67 *$ & 0 & 0 & 0 & 0 & 0 \\
\hline 12 & $11(\mathrm{I}) 1(\mathrm{C})$ & 17 & 0 & 8.3 & 25 & $100 * *$ & $92 * *$ & 50 & $100 * *$ \\
\hline
\end{tabular}

Nota. IM: Intramodal; EM: Extramodal; ED: Extra Dimensional. *Desempeño por encima del 50 \%; **Desempeño superiores al 80 \%; (I) Identidad; (F) Semejanza Forma; (C) Semejanza Color.

$50 \%$ (p2, p3 y p6). Esta disminución en el desempeño es pronunciada en la condición con TIL, pues ningún participante supera el $50 \%$.

En segunda prueba (intramodal), el desempeño fue igualmente bajo entre condiciones (excepto en p6 y p12), pero para la prueba extramodal se identificaron dos participantes cuyos resultados superaron el $80 \%$ en la condición sin TIL (p3 y p6), y uno en la condición con TIL (p12). En esta prueba, la diferencia de puntaje entre intramodal y extramodal es más amplia que para el entrenamiento 1, donde hubo una diferencia máxima de 8 (p3).

En el tercer entrenamiento se encontró un efecto diferencial entre condiciones, puesto que los participantes en la condición sin TIL tuvieron desempeños superiores al $50 \%$ y dos de ellos ( 1 y p6), superiores al $80 \%$; mientras que en la condición con TIL ningún participante superó el $50 \%$, siendo el puntaje más común $0 \%$ (p8, p9 y p11). Y, finalmente, en la tercera prueba (extradimensional), el desempeño fue bajo en todos los participantes, con excepción de p12, que aunque no obtuvo en sesiones de entrenamiento desempeños por encima del $50 \%$, sí obtuvo desempeños superiores al $80 \%$ en la segunda y tercera prueba.

\section{DISCUSIÓN}

El objetivo del Experimento I fue evaluar el efecto de una tarea de interferencia lingüistica (TIL) sobre la adquisición y transferencia de una discriminación condicional en tareas de igualación de primer orden (TIMPO), en estudiantes universitarios. Los hallazgos se discuten con base en el contraste del efecto del contacto con TIL y sin TIL, en relación con los siguientes ejes: a) adquisición y transferencia de la discriminación condicional (DC) bajo el mismo criterio de igualación - primer entrenamiento-; b) adquisición y transferencia de relaciones, o criterios de igualación novedosos; y c) cualidad del ajuste y desligamiento en pruebas de transferencia.

\section{Adquisición y transferencia bajo el mismo criterio de igualación}

Los hallazgos muestran que la TIL no afectó negativamente la adquisición de una primera discriminación condicional, ni su transferencia en pruebas intramodales o extramodales. Específicamente, tres participantes con TIL obtuvieron desempeños superiores al $80 \%$ de aciertos en el criterio de semejanza por forma en el entrenamiento, pero en la prueba inicial, en la que hubo una marcada tendencia a responder a la relación de identidad, se sugiere que tener la posibilidad de contacto lingüístico irrestricto en el entrenamiento (nominación o verbalización de los eventos de estímulo y las relaciones entre estos) no es condición necesaria para la adquisición de una discriminación condicional, al menos no de este tipo. Estos hallazgos concuerdan con los de Delgado et al., (2011), quienes, usando la metodología de igualación de la muestra de primer orden, 
variaron sistemáticamente las condiciones de presentación de tareas interferentes de carácter lingüístico sin que dicho cambio impidiera la formación de relaciones de equivalencia.

Por otro lado, en lo que respecta a las pruebas de transferencia, se ha señalado que en las pruebas intramodales y extramodales pueden tener lugar desempeños efectivos a partir de un contacto estrictamente perceptual en el entrenamiento (Ribes et al., 2005; Ribes \& Serrano, 2006); en el presente estudio, los desempeños altos de tres de los participantes sin contacto lingüístico que fueron expuestos a TIL constituyen evidencia empírica en este sentido. En esta dirección, los trabajos de Delgado, Medina y Rozo (2013) y Delgado, Medina y Jiménez (2014) exploraron la fuerte dependencia de interacciones perceptuales de la tarea de igualación de la muestra (tipo respondiente). En estos, altos desempeños se relacionaron con aspectos eminentemente atencionales (Delgado et al., 2013) o perceptuales (Delgado et al., 2014) con independencia de la descripción verbal de las relaciones; sin embargo, quedó pendiente evaluar la cualidad de las descripciones verbales en la condición sin interferencia lingüística y en la condición de interferencia.

Ahora bien, el cambio de criterio de igualación afectó negativamente el desempeño en los participantes de ambas condiciones tanto en los segundos entrenamientos como en las pruebas. Sin embargo, tal efecto fue acentuado en los participantes con TIL. Por otra parte, dada la estructura contingencial de TIMPO, no es factible programar una prueba de transferencia extrarrelacional típica, esto es, un cambio de criterio sin retroalimentación de la respuesta. En este contexto, el ajuste a los segundos y terceros entrenamientos puede considerarse como un símil de la prueba extrarrelacional.

También, se ha señalado que el desempeño efectivo en una prueba extrarrelacional requiere de un contacto lingüístico con las modalidades relevantes (Ribes et al., 2005; Ribes \& Serrano, 2006); en el presente estudio, el mismo fue limitado en la condición con TIL, y se esperaba un efecto negativo en el ajuste conductual en los cambios de criterio de igualación. Como resultado, el decremento observado en el desempeño de los participantes con TIL (salvo en p12) cuando se expusieron al cambio de criterio en el segundo entrenamiento y las pruebas fue consistente con lo esperado. Adicionalmente, lo observado en el segundo cambio de criterio (tercer entrenamiento) robustece la evidencia en este mismo sentido. Por otra parte, el alto porcentaje de respuestas correctas de p12 en la segunda y tercera prueba puede deberse a que las respuestas correctas en los entrenamientos correspondientes ( 2 y 3 ) se presentaron consecutivamente al final de estos, lo que sugiere que, aunque de forma tardía, el participante logró identificar el criterio de igualación vigente.
En la tercera prueba, que implicó una transferencia extradimensional, los desempeños fueron pobres en la mayoría de los participantes (con TIL y sin TIL). En la literatura se ha sostenido que el desempeño efectivo en transferencia extradimensional requiere que el participante haga contacto lingüístico con el criterio general de la tarea (Peña et al., 2012; Ribes et al., 2005; Ribes \& Serrano, 2006); sin embargo, en el presente estudio los hallazgos sugieren que ninguna de las dos condiciones lo promovió, pues para cada condición solo un participante (p1) en la condición sin TIL y otro (p12) en la condición con TIL obtuvieron un porcentaje alto de respuestas correctas. Sin embargo, es difícil identificar a qué se debieron sus ejecuciones en PED, dado que ambos fueron expuestos a diferentes condiciones y que su desempeño fue heterogéneo en los entrenamientos y en el resto de las pruebas.

Sobre la base de lo expuesto, es plausible sostener que la limitación del contacto lingüístico (condición con TIL) no afecta la adquisición de una primera discriminación condicional, ni el ajuste conductual a situaciones novedosas intramodales y extramodales. En consecuencia, la limitación del contacto lingüístico (en TIMPO) parece no afectar el ajuste perceptual visual, y permite el desligamiento respecto de las instancias y modalidades particulares en las que tuvo lugar la adquisición de la discriminación condicional. Sin embargo, cuando la relación o criterio de igualación cambia, la limitación del contacto lingüístico (condición con TIL) sí afecta el ajuste conductual. Esto aporta evidencia a favor del supuesto de que el contacto lingüístico con el arreglo (durante el entrenamiento) es una condición para desligarse del criterio particular en el que se adquirió la discriminación condicional inicialmente y ajustarse a nuevos criterios de relación en episodios posteriores.

Finalmente, en un análisis centrado en la flexibilidad conductual se puede sostener que limitar el contacto lingüístico (condición con TIL), si bien permite la flexibilidad respecto de las instancias y modalidades particulares de las situaciones de adquisición de la discriminación, la circunscribe al criterio particular en la que esta se adquirió. En contraparte, el contacto lingüístico sin restricciones (condición sin TIL), en tanto permite desligarse del criterio inicial de igualación y ajustarse a nuevos criterios, promueve una mayor flexibilidad conductual, lo que permite reorganizar las clases de equivalencia; tal como se reporta en Hernández, Medina y Erazo (2008). Por último, si se considera la prueba extradimensional como la que exige mayor desligamiento respecto a la condición inicial de aprendizaje (Guzmán-Díaz \& Serrano, 2013; Peña et al., 2012) esta no fue alcanzada aun cuando no se limitara el contacto lingüístico. De acuerdo con los planteamientos de Pérez-Almonacid (2012), la abstracción de las relaciones 
como entidades lingüísticas no tuvo lugar, de tal manera que tales entidades no mediaron el desempeño de los participantes en situaciones con dominios y relaciones novedosas.

\section{EXPERIMENTO II}

\section{MÉTODO}

\section{Participantes}

Para el segundo experimento participaron voluntariamente doce estudiantes universitarios de la Universidad Nacional Autónoma de México (México) de entre 18 y 23 años de edad sin experiencia en tareas de igualación de la muestra de segundo orden (TIMSO). Los participantes fueron ingenuos experimentalmente y diferentes a los del Experimento I.

\section{Aparatos y situación experimental}

El experimento tuvo lugar en las mismas condiciones locativas que el Experimento I.

\section{Diseño}

Diseño de análisis intrasujeto $(\mathrm{n}=1)$, con tarea de igualación de la muestra de segundo orden (TIMSO).

\section{Procedimiento}

En el Experimento II, los participantes pasaron por las fases de prueba inicial, entrenamiento, y pruebas de transferencia (intramodal, extramodal y extrarrelacional) (véase Tabla 3). El experimento tuvo lugar en una sola sesión con la finalidad de incrementar la validez interna. Se mantuvo el mismo criterio de doce ensayos por tipo de prueba y se expuso al mismo total (36) de ensayos en entrenamiento en ambos experimentos, en comparación con el Experimento I. A diferencia del primero, en este caso no se incluyó la prueba extradimensional.
Se utilizó como tarea base la TIMSO, variando las condiciones según el grupo, con TIL o sin TIL. La TIL consistió en que los participantes atendieran al sonido de un metrónomo e hicieran mención de una letra del abecedario en orden secuencial A a Z para cada sonido del mismo.

En cada ensayo de la TIMSO se presentaron dos Estímulos Selectores (ES) en la parte superior central de la pantalla, un Estímulo Muestra (EM) en la parte central, y cuatro Estímulos Comparativos (EC) en la parte inferior de la pantalla, todos dispuestos horizontalmente y en forma de figuras. Los arreglos se diseñaron de forma que en cada ensayo siempre se presentaba un comparativo idéntico, uno semejante en forma, uno semejante en color y uno diferente respecto de la muestra (véase Figura 7).


Figura 7. Arreglo estándar de la TIMSO. Fuente: elaboración propia.

\section{Fases del experimento II.}

\section{Prueba inicial.}

Esta consistió en 36 ensayos presentados aleatoriamente con relaciones de semejanza en color, semejanza en forma y diferencia. En este caso, los participantes no recibieron retroalimentación, y las instrucciones que se presentaron en los grupos fueron:

En las siguientes pantallas se te presentarán siete figuras: dos en la parte superior, una en el centro y cuatro en la

Tabla 3

Descripción de las fases del Experimento II

\begin{tabular}{|c|c|c|c|c|}
\hline Grupo & Prueba inicial (36) & Entren & o (36) & Pruebas(36) \\
\hline Con TIL $(n=6)$ & $\begin{array}{l}\text { Similitud forma, } \\
\text { color y diferencia. }\end{array}$ & $\begin{array}{c}\text { Entrenamiento } \\
\text { Metrónomo. }\end{array}$ & $\begin{array}{l}\text { Similitud forma, } \\
\text { Similitud color y } \\
\text { diferencia. }\end{array}$ & $\begin{array}{l}\text { Intramodal: Diferencia, simili- } \\
\text { tud forma y color. } \\
\text { Extramodal: Diferencia, simili- } \\
\text { tud forma y tamaño. }\end{array}$ \\
\hline Sin TIL $(n=6)$ & & & & Extrarrelacional: inclusión. \\
\hline
\end{tabular}


parte inferior. Elije una de las cuatro figuras de abajo que corresponda con la del centro, de acuerdo como lo indican las dos de arriba. Para registrar tu respuesta ubica el puntero del "mouse" sobre la figura que escogiste y da clic en el botón izquierdo. Si tienes dudas con las instrucciones del juego pregunta al investigador, si no, da clic en "continuar" para iniciar.

\section{Entrenamiento.}

El entrenamiento estuvo conformado por 36 ensayos: doce de similitud por forma, doce de similitud por color y doce de diferencia. Para el caso de los participantes del grupo con TIL, simultáneamente a la tarea de igualación, los participantes debían atender la TIL. Adicionalmente, previo a la tarea de igualación, y con la finalidad de que dicho grupo se familiarizara con la TIL, los participantes tuvieron que pasar por un entrenamiento al metrónomo idéntico al del Experimento I. Los arreglos de estímulo fueron los mismos entre grupos y se presentaron de manera aleatoria. En este caso, se le informó a los participantes si su respuesta era correcta o incorrecta. Y, específicamente, las instrucciones que se presentaron en esta fase para el grupo TIMSO sin TIL fueron:

En las siguientes pantallas se te presentarán siete figuras: dos en la parte superior, una en el centro y cuatro en la parte inferior. Elije una de las cuatro figuras de abajo que corresponda con la del centro, de acuerdo como lo indican las dos de arriba. Para registrar tu respuesta ubica el puntero del "mouse" sobre la figura que escogiste y da clic en el botón izquierdo. En esta ocasión se te dirá si tu respuesta fue correcta o incorrecta. Si tienes dudas con las instrucciones del juego pregunta al investigador, si no, da clic en "continuar" para iniciar.

Mientras que las instrucciones que se presentaron para el grupo TIMSO con TIL fueron:

En las siguientes pantallas se te presentarán siete figuras: dos en la parte superior, una en el centro y cuatro en la parte inferior. Elije una de las cuatro figuras de abajo que corresponda con la del centro, de acuerdo como lo indican las dos de arriba. Para registrar tu respuesta ubica el puntero del "mouse" sobre la figura que escogiste y da clic en el botón izquierdo. En esta ocasión se te dirá si tu respuesta fue correcta o incorrecta. Además, tendrás que decir una letra del abecedario en orden ascendente, según cada sonido del metrónomo. Si tienes dudas con las instrucciones del juego pregunta al investigador, si no, da clic en "continuar" para iniciar.

\section{Pruebas de transferencia.}

Las pruebas de transferencia se presentaron en 36 ensayos distribuidos en las pruebas intramodal, donde los criterios de relación fueron la similitud por forma, por color y diferencia; extramodal, donde los criterios de relación fueron la similitud por forma, por color y por tamaño; y extrarrelacional, donde el criterio de relación fue la inclusión (véase Figura 8). Los arreglos de estímulo se presentaron aleatoriamente y fueron los mismos entre grupos. En este caso, no se informó si las respuestas eran correctas o incorrectas, y las instrucciones presentadas para ambos grupos fueron:

En las siguientes pantallas se te presentarán siete figuras: dos en la parte superior, una en el centro y cuatro en la parte inferior. Elije una de las cuatro figuras de abajo que corresponda con la del centro, de acuerdo como lo indican las dos de arriba. Para registrar tu respuesta ubica el puntero del "mouse" sobre la figura que escogiste y da clic en el botón izquierdo. En esta ocasión no se te informará si tu respuesta fue correcta o no. Si tienes dudas con las instrucciones del juego pregunta al investigador, si no, da clic en "continuar" para iniciar.

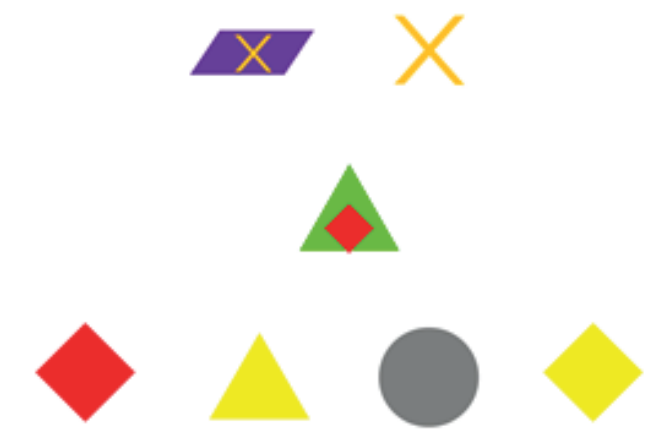

Figura 8. Ejemplo de ensayo de la prueba extrarrelacional. Fuente: elaboración propia.

\section{RESULTADOS}

El resumen de los resultados del Experimento II se presenta en la Tabla 4. En general, se observan los datos de porcentajes de acierto individuales agrupados de acuerdo a la condición experimental y en correspondencia con cada una de las fases del estudio. Al igual que en el Experimento I, se fijaron dos criterios de contraste para los desempeños individuales: desempeños por encima del $50 \%$ y desempeños superiores al $80 \%$ de aciertos. 
Tabla 4

Resumen de resultados del Experimento II

\begin{tabular}{|c|c|c|c|c|c|c|}
\hline & \multirow{2}{*}{ Participantes } & \multirow{2}{*}{$\begin{array}{c}\text { Prueba inicial } \\
\text { (36) }\end{array}$} & \multirow{2}{*}{$\begin{array}{c}\text { Entrenamiento } \\
(36)\end{array}$} & \multicolumn{3}{|c|}{ Pruebas de transferencia } \\
\hline & & & & IM (12) & $\mathrm{EM}(12)$ & $\mathrm{ER}(12)$ \\
\hline & 1 & 2 & 25 & $91 * *$ & $91 * *$ & $83 * *$ \\
\hline & 2 & 0 & 47 & $83 * *$ & $100 * *$ & 50 \\
\hline & 3 & 0 & $100 * *$ & $91 * *$ & $100 * *$ & $100 * *$ \\
\hline \multirow{3}{*}{ Sin TIL } & 4 & 8 & 19 & $66^{*}$ & $100 * *$ & $66^{*}$ \\
\hline & 5 & 0 & $80 * *$ & $83 * *$ & $100 * *$ & $100 * *$ \\
\hline & 6 & 0 & 22 & $91 * *$ & $100 * *$ & $83 * *$ \\
\hline \multirow{6}{*}{ Con TIL } & 7 & 0 & 27 & 33 & $83 * *$ & 0 \\
\hline & 8 & 36 & 44 & 25 & 33 & $58 *$ \\
\hline & 9 & 0 & $83 * *$ & $91 * *$ & $91 * *$ & $100 * *$ \\
\hline & 10 & 22 & 30 & 33 & 0 & 50 \\
\hline & 11 & 19 & $77^{*}$ & $66^{*}$ & $100 * *$ & $75^{*}$ \\
\hline & 12 & 30 & 33 & 50 & 33 & 33 \\
\hline
\end{tabular}

Nota. IM: Intramodal; EM: Extramodal; ER: Extrarrelacional. *Desempeños superiores al $50 \% * *$ Desempeños superiores al $80 \%$.

En el entrenamiento inicial (E) no se encontraron diferencias entre grupos. Pero en cada una de las dos condiciones, dos participantes superaron el $50 \%$, (p3, p5 / p9, p11), con salvedad de p11, quien obtuvo puntaje superior al $80 \%$. En la fase de pruebas (intramodal) se registró un efecto diferencial de la condición con TIL en comparación con los participantes de la condición sin TIL, quienes tuvieron desempeños superiores al $50 \%$ y cinco (de seis), por encima del $80 \%$. En tanto que en la condición con TIL dos participantes superaron el $50 \%$, y uno (de seis) el $80 \%$ de aciertos.

De manera consistente con la prueba intramodal, en la prueba extramodal se registraron diferencias entre condiciones, pues todos los participantes de la condición sin TIL superaron el $80 \%$ de aciertos, mientras que los participantes con TIL obtuvieron resultados superiores al $80 \%$ (tres participantes) y resultados inferiores al $50 \%$ (tres participantes), incluyendo un solo desempeño de $0 \%$ (p10). Por otra parte, en la prueba extrarrelacional, cuatro participantes sin TIL superaron el $80 \%$ de aciertos, con dos casos de desempeño de $100 \%$ (p3 y p5), mientras que en la condición con TIL, un participante logró un desempeño por encima del $80 \%$ (p9), y dos participantes (p8 y p11) desempeños mayores al $50 \%$.

Al contrastar el desempeño entre fases (entrenamientopruebas), los participantes de la condición sin TIL mejoraron su desempeño en la fase de pruebas respecto al entrenamiento. En contraparte, los participantes con TIL no mejoraron su desempeño en la fase de pruebas, con excepción de un participante (p7) en la prueba extramodal.
Finalmente, para ambas condiciones, los participantes con desempeños superiores al $80 \%$ en entrenamiento inicial tuvieron desempeños superiores al $50 \%$ y al $80 \%$ en la fase de pruebas.

\section{DISCUSIÓN}

El objetivo del Experimento II fue evaluar el efecto de una tarea de interferencia lingüistica (TIL) sobre la adquisición y transferencia de una discriminación condicional en tareas de igualación de segundo orden (TIMSO), en estudiantes universitarios. Los hallazgos se discuten con base en el contraste entre el contacto con TIL y sin TIL, en relación con los ejes de adquisición y transferencia de la discriminación condicional, y de cualidad del ajuste y desligamiento conductual en pruebas de transferencia.

Los hallazgos muestran que la condición con TIL no afectó la adquisición de la discriminación respecto a la condición sin TIL. En consecuencia, se puede señalar que limitar el contacto lingüístico no necesariamente impide la adquisición de la discriminación condicional en este tipo de tareas. Este punto coincide con otros estudios en los que se ha señalado que el contacto lingüístico irrestricto no es necesario para la adquisición de respuestas derivadas, emergentes o congruentes con un entrenamiento inicial (Delgado et al., 2011; León, 2015; Peña et al., 2012). Adicionalmente, con base en los resultados, se puede sostener que en la mayoría de los participantes el desempeño en entrenamiento se relacionó positivamente con el desempeño en los tres 
tipos de prueba en la condición con TIL; mientras que en la condición sin TIL los desempeños bajos en entrenamiento no se relacionaron con desempeños bajos en pruebas.

Como ya se mencionó, de acuerdo con lo señalado por algunos autores (Peña et al., 2012; Ribes, 2005; Ribes \& Serrano, 2006), los distintos tipos de pruebas de transferencia empleados en este estudio implican diferentes tipos de contacto con la tarea o distintas cualidades del ajuste conductual. Específicamente, se ha dicho que las pruebas intramodal y extramodal pueden ser respondidas a partir de un contacto estrictamente perceptual con la tarea. Siguiendo esta línea, no deberían observarse diferencias relevantes en estas pruebas entre los participantes con TIL y sin TIL, ya que lo que se limitó fue el contacto lingüístico, pero no el perceptual; sin embargo, sí se observaron diferencias y los participantes sin TIL obtuvieron mejores desempeños.

Con base en lo anterior, se puede decir que el contacto lingüístico sin interferencia no fue una condición necesaria para la transferencia intra y extramodal — dado que dos participantes con TIL tuvieron desempeños altos - aunque sí fue un facilitador de dicha transferencia. Como lo señalan Delgado y Hayes (2013) y Pérez-Almonacid (2012), aunque aún no es claro cuál es el rol de las verbalizaciones o mediaciones verbales en las tareas de transferencia del aprendizaje, interferir con estas en el entrenamiento no resulta ser una condición que impida per se la transferencia, como han señalado algunos teóricos previamente (BarnesHolmes, Rodríguez \& Whelan, 2005).

Respecto a la prueba de transferencia extrarrelacional, se ha señalado que esta requiere de un contacto lingüístico con las modalidades y criterios relevantes en los episodios de entrenamiento, sobre todo, argumentando que tal contacto posibilita el desligamiento no solo de las instancias y modalidades particulares de adquisición (lo que es posible únicamente con el contacto perceptual) sino además del criterio de relación (Peña et al., 2012; Ribes \& Serrano, 2006). En este sentido, si la condición con TIL limitó el contacto lingüístico, se esperaría que los participantes expuestos a esta condición no presentaran desempeños altos en esta prueba. Sin embargo, tres participantes en esta condición obtuvieron más del $50 \%$ de aciertos en la prueba extrarrelacional y uno de ellos obtuvo más del $80 \%$ de aciertos.

Respecto a estos datos, hay dos conclusiones importantes: por un lado, aunque contradictorios con los supuestos apuntados previamente, los resultados son consistentes con evidencia empírica (León, 2015) y con trabajos de revisión (Peña et al., 2012) en los que se ha sugerido que el contacto lingüístico no es una condición necesaria para tener desempeños altos en pruebas extrarrelaciones en TIMSO; $y$, por otro, que debido a que en el arreglo de relación por inclusión el primer estímulo selector incluye al segundo, el participante podría no haber respondido necesariamente a la relación entre estímulos, sino simplemente a las propiedades absolutas del estímulo "incluido", de forma que eligiera un estímulo que igualara tales propiedades. De ser el caso, la respuesta estaría ligada a las propiedades aparentes de los estímulos y no requeriría de la mediación lingüística (lo que explicaría los altos desempeños de los participantes con TIL).

En posteriores experimentos deben utilizarse arreglos que permitan diferenciar con mayor claridad el responder genuinamente relacional de aquel vinculado a las propiedades aparentes de los estímulos en la prueba extrarrelacional. Finalmente, la observación de los desempeños entre fases sugiere que el contacto lingüístico no limitado (condición sin TIL) favoreció la flexibilidad con respecto al entrenamiento incluso en los participantes con desempeños bajos en las primeras fases.

\section{DISCUSIÓN GENERAL}

En el estudio de la discriminación condicional (DC) en humanos ha sido ampliamente estudiado el efecto de agregar componentes lingüísticos, ya sea en términos de las instrucciones presentadas a los participantes (Arismendi \& Fiorentini, 2014), en el estudio de las descripciones acerca de los aspectos tomados en cuenta para solucionar una tarea (Cepeda et al., 1991; Ribes et al., 1992), o en la interferencia con el objetivo de limitar la interacción lingüística con las tareas (Delgado et al., 2011; León, Félix, García \& Medina, en prensa).

En la mayor parte de estas investigaciones se ha señalado que el contacto lingüístico con las propiedades y criterios de la tarea es un factor crítico tanto en la adquisición de la DC como en su transferencia (Barnes-Holmes et al., 2005; Peña et al., 2012; Pérez-Fernández, 2015), especialmente del tipo extrarrelacional y extradimensional (GuzmánDíaz \& Serrano, 2013; Ribes, et al., 2005). Sin embargo, análisis empíricos y conceptuales recientes cuestionan este supuesto (Delgado \& Hayes, 2013; León, 2015; Peña et al., 2012). Llama la atención que hasta el momento el grueso de los estudios del área interesados en identificar el papel funcional del contacto lingüístico se han limitado a agregar componentes de este tipo y no han explorado sistemáticamente el efecto de su restricción. En este contexto, los experimentos reportados contrastan el efecto de limitar el contacto lingüístico en tareas de igualación de primer y segundo orden que suponen ajustes conductuales diferentes en complejidad (León, 2015; Peña et al., 2012; Ribes \& Serrano, 2006), a fin de identificar la cualidad del 
ajuste afectado por la limitación del contacto lingüístico (con TIL) en los dos tipos de tarea de igualación típicos del campo de estudio.

Como resultado, se obtuvo que la limitación del contacto lingüístico (con TIL) no afectó la adquisición por tipo de tarea de igualación, es decir que ni en TIMPO ni en TIMSO se apreciaron efectos diferenciales entre las condiciones con TIL frente a sin TIL. Sin embargo, en las pruebas de transferencia sí se observaron efectos diferentes de estas condiciones en cada tipo de tarea de igualación.

Por otro lado, mientras que en TIMPO la limitación del contacto lingüístico (con TIL) no tuvo efecto sobre el desempeño de los participantes en las pruebas intramodal y extramodal, sí hubo limitación en TIMSO. Esta diferencia es relevante porque considerando que las pruebas intramodales y extramodales exigen un contacto de tipo perceptual visual, cabría esperarse que no hubiera diferencias por la limitación del contacto lingüístico (con TIL) ni en TIMPO ni en TIMSO.

Los hallazgos sugieren que en TIMPO la interferencia del contacto lingüístico no tiene un papel relevante en la transferencia intramodal y extramodal; mientras que en TIMSO contar con la posibilidad de contacto lingüístico no es necesario - dado que hubo dos participantes con TIL que tuvieron buenos desempeños en pruebas- pero sí es un facilitador de la transferencia.

En este sentido, es plausible señalar que en TIMSO el contacto lingüístico facilita el ajuste conductual de tipo perceptual sin que necesariamente sea el factor estructurante de la interacción, como se documenta en otro estudio reciente (Meraz, 2016). De este modo, las diferencias señaladas pueden deberse a las características funcionales de cada tipo de tarea (Ribes \& Torres, 2001). Mientras que la identificación del criterio de igualación en primer orden depende críticamente de la retroalimentación, en segundo orden el criterio de igualación está ejemplificado por los estímulos de segundo orden y la identificación de este se facilita, aunque no depende, con el reconocimiento verbal.

En lo que concierne al ajuste conductual ante el cambio de criterios de igualación (transferencia extrarrelacional), se esperaba que este se viera afectado negativamente por la condición con TIL en ambos tipos de tarea, en consideración al supuesto de que este tipo de pruebas de transferencia requiere del reconocimiento lingüístico de las modalidades y criterios relevantes en la igualación durante el entrenamiento (Peña et al., 2012; Ribes, 2005; Ribes \& Serrano, 2006).

En TIMPO, la condición con TIL no solo interfirió con el ajuste en el cambio de criterio, sino que, al parecer, lo imposibilitó incluso en participantes que obtuvieron desempeños altos en el primer entrenamiento y primera prueba intramodal y extramodal. Sin embargo, en TIMSO la condición con TIL no afectó a los participantes que tuvieron desempeños altos en el entrenamiento a pesar de que se limitó el contacto lingüístico con la tarea. Estos datos son consistentes con lo señalado por León (2015) y por Peña et al. (2012) respecto al carácter no necesario del contacto lingüístico en entrenamiento para responder satisfactoriamente en pruebas extrarrelacionales en TIMSO, y con los hallazgos de Delgado et al. (2013), y Delgado et al. (2014), en los que los arreglos no lingüísticos sino perceptuales asociados con la tarea fungieron como facilitadores del éxito en fase de pruebas.

La aparente anomalía observada en el segundo experimento de este trabajo puede comprenderse si se tiene en cuenta que en el arreglo de TIMSO el criterio de relación se presenta y actualiza entre fases, ensayo a ensayo, con los estímulos de segundo orden. Esta explicitación posibilita el contacto con el criterio de igualación independientemente de la retroalimentación del ensayo vigente, de la exposición a ensayos previos y del tipo de contacto que haya podido tener lugar en estos (como un contacto lingüístico limitado o estrictamente perceptual de forma visual). En este sentido, la interacción en TIMSO puede ser efectiva circunscribiéndose únicamente al ensayo presente; paradójicamente, en TIMPO, que se considera típicamente una tarea menos compleja funcionalmente, para identificarse el criterio de igualación se debe hacer contacto generalmente con una colección de episodios, pues no hay nada en un ensayo particular que "contenga" por sí mismo el criterio. De hecho, el contacto con un cambio de criterio en TIMPO tiene lugar siempre de manera posterior a la respuesta del participante a través de la retroalimentación.

En conclusión, el análisis realizado y los hallazgos del estudio sugieren que la prueba de transferencia extrarrelacional en TIMSO no es un buen indicador de comportamiento lingüísticamente mediado. Sin embargo, se reconoce la necesidad de estudios con arreglos metodológicos más robustos a fin de tener evidencia empírica más sólida respecto a la relación entre el comportamiento mediado lingüísticamente y el comportamiento genuinamente relacional.

Cabe resaltar que un efecto análogo es el reportado por Arismendi y Fiorentini (2014), pues al comparar la efectividad del procedimiento estándar de TIMPO frente a uno con instrucciones que señalan los criterios, el desempeño de los participantes expuestos a instrucciones (explicitación del criterio previo a la tarea) fue superior al de los participantes que no se expusieron a dicho criterio, sino al historial de episodios conductuales de reforzamiento (procedimiento estándar). Salvando las diferencias procedimentales entre estudios, es contrastable que al hacer explícito el criterio de la tarea - sea a través de estímulos de segundo orden o de instrucciones - se promueven interacciones ligadas 
situacionalmente y, por tanto, estas podrían no representar buenos ejemplares metodológicos para la evaluación de la abstracción de relaciones a otros dominios o relaciones (Pérez-Almonacid, 2012).

Finalmente, sobre la limitación del contacto lingüístico y sus efectos diferenciales en el desligamiento y la cualidad del ajuste en pruebas, los hallazgos sugieren que en TIMPO la limitación de la interacción lingüística con la tarea limitó el contacto a un nivel perceptual-visual, lo que vincula el comportamiento al criterio de igualación particular de la adquisición inicial; mientras que, en TIMSO, la condición con TIL no ligó el comportamiento a un criterio particular. Sin embargo, como lo sugieren los hallazgos del presente estudio, responder correctamente en este tipo de tareas ante el cambio de criterio puede que no sea necesariamente un indicador de un contacto extraepisódico posibilitado lingüísticamente.

\section{REFERENCIAS}

Arismendi, M., \& Fiorentini, L. (septiembre, 2014). Formación de clases de equivalencia de estímulos: comparación de la eficacia del entrenamiento por reforzamiento y por instrucciones. En D. Laznik (Coordinador). VI Congreso Internacional de Investigación y Práctica Profesional en Psicología XXI Jornadas de Investigación Décimo Encuentro de Investigadores en Psicología del MERCOSUR. Congreso llevado a cabo en la Facultad de Psicología, Universidad de Buenos Aires, Buenos Aires. Recuperado de http://www. aacademica.org/000-035/465.

Barnes-Holmes, D., Rodríguez, M., \& Whelan, R. (2005). La teoría de los marcos relacionales y el análisis experimental el lenguaje y la cognición. Revista Latinoamericana de Psicología, 37, 255-275. Recuperado de http://pepsic.bvsalud. org/pdf/rlp/v37n2/v37n2a03.pdf

Cepeda, M.L., Hickman, H., Moreno, D., \& Ribes, E. (1991). The effect of prior selection of verbal descriptions of stimulus relations upon performance in conditional discrimination in humans. Revista Mexicana de Análisis de la Conducta, 17, 53-80. Recuperado de http://rmac-mx.org/wpcontent/uploads/2013/05/VOL-17-N-1-Y-2-53-79.pdf

Delgado, D., \& Hayes, L. (2013). The integration of learning paradigms by way of a non-causal analysis of behavioral events. Conductual, 1, 39-54. Recuperado de http://conductual.com/content/integration-learning-paradigms-way-noncausal-analysis-behavioral-events

Delgado, D., Medina, I., \& Jiménez, L. (2014). Relaciones de equivalencia y estilo cognitivo: hallazgos de una relación no explorada. Suma Psicológica, 21, 19-27. doi: https://doi. org/10.1016/S0121-4381(14)70003-7

Delgado, D., Medina, I., \& Rozo, M. (2013). Evaluación de la habituación a las condiciones estimulativas del proced- imiento de igualación a la muestra. Suma Psicológica, 20, 15-29. DOI: 10.14349/sumapsi2013.1292

Delgado, D., Medina, I., \& Soto, J. (2011). El lenguaje como mediador de la transferencia de funciones: ¿Es necesario nominar para relacionar? Revista Mexicana de Análisis de la Conducta, 37, 31-52.

Guzmán-Díaz, G., \& Serrano, M. (2013). Propiedades fisicoquímicas versus lingüísticas en la adquisición y transferencia de discriminaciones condicionales por humanos. Acta Comportamentalia, 21, 435-444. Recuperado de http:// pepsic.bvsalud.org/scielo.php?script=sci_arttext\&pid $=$ S0188-81452013000400003

Hernández, A., Medina, I., \& Erazo, L. (2008). Resurgencia de conductas simbólicas: una aproximación experimental. Acta Colombiana de Psicología, 11(2), 141-151.

León, A. (2015). Modo de contacto: efecto sobre la adquisición y transferencia de una discriminación condicional de segundo orden y la emergencia de reglas. Acta Colombiana de Psicología, 18, 25-36. DOI: 10.14718/ACP.2015.18.1.3

León, A., Félix, I., García, \& Medina, I. (en prensa). Efecto de limitar el contacto lingüístico en la adquisición y transferencia de una discriminación condicional en tareas de igualación con estímulos de morfología convencional.

Meraz, E. (2016). Análisis teórico y experimental de la función selectora lingüistica (Tesis doctoral). Universidad Veracruzana, Xalapa.

Moreno, D., Ribes, E., \& Martínez, H. (1994). Evaluación experimental de la interacción entre el tipo de prueba de transferencia y la retroalimentación en una tarea de discriminación condicional bajo aprendizaje observacional. Revista Latina de Pensamiento y Lenguaje, 2, 245-286. Recuperado de http://www.academia.edu/download/33812122/ Evaluacion_Experimental_de_la_interaccion_entre_el_ tipo_de_pruebas_de_transferencia_y_la_retroalimentacion_en_una_tarea.....pdf

Peña, T., Ordóñez, S., Fonseca, J., \& Fonseca, L. (2012). La investigación empírica de la función sustitutiva referencial. En A. Padilla \& R. Pérez-Almonacid (Eds.), La función sustitutiva referencial, análisis histórico-crítico/avances y perspectivas (pp. 35-100). New Orleans, LA, EEUU: University Presss of the South.

Pérez-Almonacid, R. (2012) El análisis conductista del pensamiento humano. Acta Comportamentalia, 20, 49-68. Recuperado de http://pepsic.bvsalud.org/scielo.php?script=sci_ arttext\&pid=S0188-81452012000400006

Pérez-Almonacid, R. (2015). Desligamiento funcional y causalidad eficiente: Comentario a El desligamiento funcional y la causalidad aristotélica: un análisis teórico de Ribes Iñesta. Acta Comportamentalia, 23, 35-43. Recuperado de http://pepsic.bvsalud.org/scielo.php?script=sci_arttext\&pid $=\mathrm{S} 0188-81452015000100004$

Pérez-Fernández, V. (2015). Clases de equivalencia y conducta verbal. Conductual, 3, 26-44. Recuperado de http://conductual.com/content/clases-de-equivalencia-y-conducta-verbal 
Ribes, E. (1990). Psicología general. México, DF: Trillas.

Ribes, E. (2000). Instructions, rules, and abstractions: a misconstrued relation. Behavior \& Philosophy, 28, 41-55. Recuperado de http://store.behavior.org/httpdocs/resources/90.pdf

Ribes, E. (2015). El desligamiento funcional y la causalidad Aristotélica: Un análisis teórico. Acta Comportamentalia, 23, 5-15. Recuperado de http://pepsic.bvsalud.org/scielo. php?script=sci_arttext\&pid=S0188-81452015000100001

Ribes, E., \& Castillo, A. (1998). Interacción del tipo de entrenamiento y el tipo de respuesta de igualación en transferencia en una discriminación condicional de segundo orden. Acta Comportamentalia, 6, 5-20. Recuperado de http:// www.academia.edu/download/33412411/Interaccion_del_ tipo_de_entrenamiento_y_el_tipo_de_respuesta_de_igualacion_en_transferencia_en_una_discriminacion_condicional_de_segundo.pdf

Ribes, E., \& López, F. (1985). Teoría de la conducta. Un análisis de campo y paramétrico. México, DF: Trillas.

Ribes, E., \& Martínez, H. (1990). Interaction of contingencies and rule instructions in the performance of human subjects in conditional discriminations. The Psychological Record, 40, 565-586. Recuperado de http:/www.academia.edu/ download/33764749/Interaction_of_contingencies_and_ rule_instructions_in_the_performance_of_human_subjects_in_conditional_discrimination.pdf

Ribes, E., \& Serrano, M. (2006). Efectos de tres tipos de preentrenamiento en la adquisición y transferencia de una tarea de igualación de la muestra. Acta Comportamentalia, 14, 145-169. Recuperado de http://pepsic.bvsalud.org/scielo. php?script=sci_arttext\&pid=S0188-81452006000200003

Ribes, E., \& Torres, C. (2001). Un estudio comparativo de los entrenamientos de primer y segundo orden en igualación de la muestra. Revista Mexicana de Análisis de la Conducta, 27, 385-401. Recuperado de http://rmac-mx.org/wp-content/uploads/2013/05/Vol-27-n-3-385-401.pdf

Ribes, E., Barrera, J.A., \& Cabrera, F. (1998). Interacción del entrenamiento observacional en igualación a la muestra de primer orden con el tipo de retroalimentación y respuesta de igualación durante las pruebas de transferencia. Revista Mexicana de Análisis de la Conducta, 24, 339-352. Recuperado de http://www.academia.edu/download/33427461/ Interaccion_del_entrenamiento_observacional_en_iguala- cion_de_la_muestra_de_primer_orden_con_el_tipo_de retroalimentacion_y_respuesta_de..pdf

Ribes, E., Domínguez, M., Tena, O., \& Martínez, H. (1992). Efecto diferencial de la elección de textos descriptivos de las contingencias entre estímulos antes y después de la respuesta de igualación en una tarea de discriminación condicional. Revista Mexicana de Análisis de la Conducta, 18, 31-59. Recuperado de http://revistas.unam.mx/index.php/ rmac/article/download/23373/23854

Ribes, E., Moreno, D., \& Martínez, C. (1995b). Interacción del entrenamiento observacional e instrumental con pruebas de transferencia verbales y no verbales en la adquisición y mantenimiento de una discriminación condicional. Revista Mexicana de Análisis de la Conducta, 21, 23-45.

Ribes, E., Moreno, D., \& Martínez, H. (1995a). Efectos de distintos criterios verbales de igualación y transferencia de la discriminación condicional de segundo orden en humanos. Acta Comportamentalia, 3, 27-54. Recuperado de http://revistas.unam.mx/index.php/acom/article/viewFile/18311/17395

Ribes, E., Ontiveros, S., Torres, C., Calderón, G., Carvajal, J., Martínez, C., \& Vargas, I. (2005). La igualación de la muestra como selección de estímulos de segundo orden: Efectos de dos procedimientos. Revista Mexicana de Análisis de la Conducta, 31, 1-22.Recuperado de http://journals.iztacala. unam.mx/index.php/smac/article/viewFile/33/35

Ribes, E., Torres, C., \& Barrera, A. (1995). Interacción del tipo de entrenamiento, morfología de la respuesta y demora en la retroalimentación en la adquisición y transferencia de la ejecución en una tarea de igualación a la muestra de primer orden en humanos. Revista Mexicana de Análisis de la Conducta, 21, 145-164. Recuperado de http://www.academia. edu/download/34117468/Interaccion_del_tipo_de_entrenamiento_morfologia_de la_respuesta_y_demora_de_la retroalimentacion_en_la_adquisicion_y_transferencia_de_. pdf

Trigo, E., Martínez, R., \& Moreno, R. (1995). Rule performance and generalization in a matching-to-sample task. The Psychological Record, 45, 223-240. Recuperado de http:// search.proquest.com/openview/765e832564e97ffb 7 fea 191 7b7796f4f $/ 1$ ?pq-origsite $=$ gscholar\&cbl $=1817765$ 